\title{
Introduction of a method for calculating the investment activity of an enterprise (evidence from wood-processing enterprises)
}

\author{
Olga Polyanskaya ${ }^{1 *}$, Veronika Bespalova ${ }^{1}$, and Viktoria Sokolova ${ }^{1}$ \\ ${ }^{1}$ Saint Petersburg State Forest Technical University, Saint Petersburg, Russia
}

\begin{abstract}
In the current economic conditions, the industry is interested in implementing new innovative processes, products and, consequently, it needs investment. This problem also concerns the woodworking industry that suffers from a lack of modern equipment that allows for a more comprehensive use of the available raw materials and proportional quality of the end product. In order to analyze the situation with each industry (particularly woodworking), an innovative production system is proposed that is based on determining the level of an enterprise using design coefficients. Based on this analysis, an appropriate strategy of the company development can be adopted. The calculated index of innovation activity can constitute a reason for the enterprise to strengthen its innovative potential and carry out efficient innovation activity.
\end{abstract}

\section{Introduction}

Forests are often called the lungs of the planet, and most of the forest reserves are concentrated in Russia. To date, Russia owns a quarter of the world's wood reserves [13]. However, the country is far from being the best in global woodwork trading. The forest industry's share in the national industry is less than $4 \%$ [18]. To date, the woodwork industry in Russia is characterized by low efficiency, which affects the economic performance of the enterprises accordingly and, in general, does not meet the state's economic interests. There are many factors hindering the development of the forest industry [18]. The major ones are:

- high depreciation of fixed assets;

- low investment activity;

- insufficient degree of processing;

- $\quad$ poor quality of all-weather logging roads;

- low competitiveness of the products;

- inefficient use of the working capital.

The development of the woodwork industry is hindered by the lack of innovative technologies for the exploitation of the raw and waste wood, the average share of which in the raw wood is approx. 45\% [12]. These technologies do exist and are widely used outside Russia. For instance, in Sweden, wood processing reaches $98 \%$, and in Finland 97\%.

In the past century, waste wood was used for producing chip, sawn lumber, split billets, container assemblies, and other types of end products [21]. Today, this kind of material is used in different, more versatile ways mainly due to the innovative development of the chemical industry. In particular, it is proved that chips can be used to produce sulphate cellulose, and charcoal and activated charcoal can be obtained through thermochemical treatment $[4,12]$. However, chip is a popular material for decorating kindergartens and playgrounds and for the production of various composite materials widely used in the furniture and construction industries.

Back in 1971, the USSR forest industry had two main objectives:

- provide for the further development of the woodwork industry, taking into account the complex processing of raw wood;

- $\quad$ expand the use of process feedstock in the paper and pulp industry, chipboards and chip.

\section{Relevance}

The above objectives remain relevant today.

In order to change the current situation in the woodwork industry, we need to implement an innovative approach to its development as the most efficient variant of providing the home market with domestic production and increase the degree of processing.

This problematic has been studied by the following Russian researchers: Z. A. Dikaya, E. D. Shchetinina, M. V. Egorova, E. P. Amosenko, and others.

\section{Research objective}

In order to solve the formulated problem, we have developed and suggested a method for calculating the innovation activity index for wood-processing enterprises. The result of implementing the method should be the adoption of competent managerial 
decisions on introducing innovations. The results of their implementation include the satisfaction of the domestic demand (through improving the marketability of domestic products) as well as increasing the industry's contribution to the economic development of the regions.

\section{Theoretical part}

Innovating is a set of activities aimed at improving the efficiency of the production process and the entire financial and economic activity of the enterprise in general [2].

In modern conditions, this is mainly done by increasing the competitive performance of enterprises through innovative products and processes $[1,3,5,7]$. As for the innovative products in the woodwork industry, innovations in assortment policies, raw and processed materials, fittings, and tools can be suggested as the most relevant; possible innovative processes include new production technologies and methods of production management $[6,8,9]$.

The main trend that is commonly considered to be hindering the innovation activity in the woodwork industry is the lack of investment in this sector. This is mainly due to the high risk and the long payback period of such investments. However, some types of innovating can be carried out by the enterprises routinely without much additional investment: improving the marketing activities, quality of management, and the application and integration of new methods into the management system of the enterprise.

A study conducted by the researchers of the Chair of Economics and Management of Wood Processing Plants at Saint Petersburg Kirov State Forest Technical University on a number of plywood-producing plants showed that the index of innovation activity is rather low: between 0.298 and 0.395 . This highlights the low innovative ability of the enterprises. The situation in the wood processing industry is challenging. Therefore, the Innovative Production System (IPS) taking into account both the specifics of the enterprise and the external environmental conditions was suggested for implementation in several enterprises.

Each company is a unique open economic system with its own peculiarities of operation and production. The innovative changes should, therefore, be implemented taking into account the peculiar features of the enterprise and the requirements of the external environment (the market). The main strategic advantage of any enterprise depends on the continuous improvement of its productive capacities through innovation.

Therefore, the following directions of operation have been identified in the introduction of an innovative system:

1. development and implementation of systematic marketing;

2. research and analysis of new growth areas for the enterprise;

3. improvement of the organizational and management structure;
4. comprehensive processing of wood waste and low grade raw materials;

5. providing a modern material and technical base;

6. updating and maximal use of the production capacity;

7. efficient use of the working capital of the enterprise;

8. introduction of innovations in production and management.

Of the many factors that affect innovation systems in production, the main ones in our opinion are: the productive capacity, the human resources capacity and the investment potential [10,11, 15, 16, 20, 23].

Qualitative and quantitative analysis of business innovation activity measure the ability of the enterprise to innovate $[3,17,19,22]$.

Based on the data collected on the wood-processing industry, a calculation of innovation activity has been made for several enterprises in the industry featuring the following parameters:

1.Low-waste production.

In the woodworking industry, this parameter is assessed through the rate of comprehensive utilization of material $\left(C_{u}\right)$

$$
C_{u}=\frac{V_{0}+V_{d}}{V_{s}}
$$

where $V_{o}$ is the volume of principal products produced from raw wood, $\mathrm{m}^{3}, V_{d}$ is the output from the processing of waste from primary products, $\mathrm{m}^{3}$., $V_{s}$ volume of raw material written off for production, $\mathrm{m}^{3}$.

Thus, it can be assumed that the rate of comprehensive utilization of raw materials should grow and the cost of comprehensive utilization of raw materials should fall. In terms of productive capacities, to be considered innovative, an enterprise needs to comply with the following two conditions:

$$
\begin{aligned}
& C_{u} \Rightarrow 1 \\
& \frac{V_{n}}{V_{c}} \Rightarrow \max
\end{aligned}
$$

where $V_{n}$ is the profit before corporate income tax and interest costs,

$V_{c}$ stands for the costs of production.

2.Availability of the staff engaged in research and development $\left(U_{s}\right)$ :

$$
U_{s}=\frac{q_{r d}}{q_{i p}}
$$


where $q_{i p}$ is the total number of industrial personnel; $q_{r d}$ is the number of employees engaged in research and development.

There are no restrictions on this parameter. It is the enterprises that decide how many employees should engage in research and development.

3. The share of equipment engaged in innovation in the total equipment $\left(U_{e q}\right)$.

In calculating this parameter, it should be noted that, in accordance with accounting rules, the cost of the equipment is reflected with respect to its residual value. If the company acquires new equipment that is going to be directly connected to innovation activity, its cost is going to be relatively high. Therefore, in order to prevent distortion of this indicator, it is recommended to account for all the equipment with respect to its depreciation over the accounting period using the index method.

$$
U_{e q}=\frac{F_{i n n}}{F_{o}}
$$

Where $F_{i n n}$ is the value of the property used for testing and research; $F_{o}$ is the total cost of machinery and equipment used in the manufacturing of the products.

4.The share of intangible assets connected with implementation of innovation in the total intangible assets of the enterprise $U_{i a}$.

In calculating this parameter, the comments on the cost and depreciation in p. 3 should be taken into account; the index method should be used for calculation.

$$
U_{i a}=\frac{F_{i a}}{F_{o n m}}
$$

where $F_{i a}$ is the cost of intangible assets employed in innovation; $F_{\text {onm }}$ - total value of intangible assets in the enterprise.

5.Availability of funds for the development of innovative activities $\left(U_{i n v}\right)$

$$
U_{i n v}=\frac{U_{o}}{U_{t o t}}
$$

where $U_{o}$ is the availability of the enterprise's own funds; $U_{\text {tot }}$ is the total amount of investment necessary for the implementation of the innovative project.

The innovation development activity index is the sum of all the five parameters:
$U_{i n n}=\sum\left(C_{u}+U_{s}+U_{e q}+U_{i a}+U_{i n v}\right)$

The following numerical intervals of the innovation development activity index can be used to describe and further choose the innovation strategy: If the innovation development activity index:

- ranges from 2.41 to 3 , it is the advancing strategy;

- ranges from 1.7 to 2.41 , it is the defensive strategy;

- $\quad$ ranges from 0 to 1.7 , use the imitation strategy.

It should be noted that, for calculating the innovation activity index in the enterprises outside of the woodworking industry, the formula (8) can be written as follows:

$$
U_{i n n}=\sum\left(U_{s}+U_{e q}+U_{i a}+U_{i n v}\right)
$$

The numeric intervals of the innovative activity index in this case are going to be somewhat different:

- $\quad$ ranges from 1.41 to 2 , the advancing strategy;

- $\quad$ ranges from 0.7 to 1.41 , the defensive strategy;

- $\quad$ ranges from 0 to 0.7 , the imitation strategy $[3,10$, $11]$.

The formula (9) can include additional parameters depending on the industry of the enterprise. However, its interpretation should be studied and calculated by experts in the respective industry, because the numeric intervals of the index of innovative activity will also be different.

\section{Practical significance}

Based on the research method suggested above (formula No. 8), the professors of Saint Petersburg Kirov State University analyzed the data of a number of enterprises. All the studies were conducted on the data of existing enterprises), and for information security purposes, the enterprises are going to be presented as A, B, C, D, E, F ( $\mathrm{A}$ is engaged in furniture production; $\mathrm{B}$ in sawing production; $\mathrm{c}$ in furniture manufacturing; $\mathrm{D}$ in plywood production; E in woodworking (joinery)) $[10,11]$.

The enterprises that provided the data for the study are typical representatives of the woodworking industry, so let us examine the results of the study as an established pattern.

According to study data and the performed calculations, the integral indices of innovation activity are as follows: Table 1 .

Table 1. Determination of the enterprise activity index.

\begin{tabular}{|c|c|c|c|c|c|c|}
\hline Parameters & $\begin{array}{c}\text { Sym- } \\
\text { bol }\end{array}$ & A & B & C & D & E \\
\hline 1 & 2 & 3 & 4 & 5 & 6 & 7 \\
\hline $\begin{array}{l}\text { 1. Number } \\
\text { of industrial } \\
\text { personnel, } \\
\text { persons }\end{array}$ & $q_{i p}$ & 88 & 62 & 615 & 471 & 43 \\
\hline
\end{tabular}




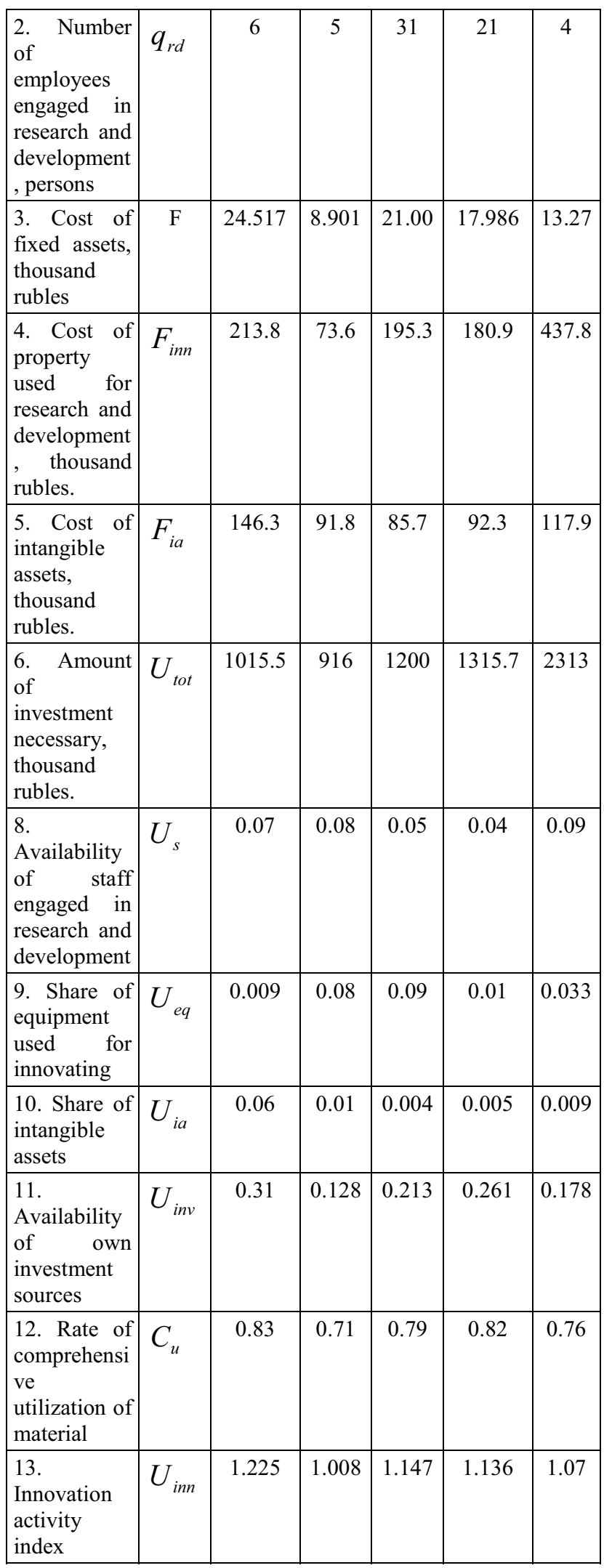

On the basis of the proposed simulation model, the following conclusions can be made.

\section{Conclusion}

The study results indicate that the innovation activity index in the enterprises of the Russian Federation woodworking industry is at a fairly low level and match the simulation strategy for the development of innovation in the industry.

The proposed innovation development activity index for woodworking enterprises includes all the basic parameters that can be used to evaluate the innovation development of the enterprises in the relevant industry. Excluding the rate of the comprehensive utilization of the material from the proposed formula provides us with an integrated index of innovation activity for any enterprises.

Introduction of the innovative production systems in the future will enable the enterprise to move to the defensive and even the advancing strategy, which will promote the efficient development of not only the woodworking industry, but also the country as a whole.

\section{References}

1. E.P. Amosenko, V.A. Bazhanov, The Region: Economy and Sociology, 450 (2006)

2. S.D. Arshlanov, Fundamental Studies, 9-1, 111-115 (2015)

3. V.V. Bespalova, O.A. Polyanskaya, Herald of Belgorod Shukhov State Technological University, 3, 183-186 (2016)

4. S.K. Goroshko, All-Soviet Science, Research and Design Institute of Economics, Industrial Management and Information in Forestry, Paper and Pulp and Wood Processing Industry, 36 (1974)

5. T.N. Danilova, V.A. Grishchenko, Regional Economics: Theory and Practice, 5, 78-80 (2015)

6. A.G. Devyatkin, Approbation, 9(36), 57-59 (2015)

7. Y.A. Doroshenko, Belgorod State Technocal University Publishing, 133 (2012)

8. Y.A. Doroshenko, S.M. Bukhonova, E.I. Tomilina, A.P. Taburchak, Herald of Belgorod Shukhov State Technological University, 1, 130-133 (2007)

9. M.V. Yegorova, Regional Economics: Theory and Practice, 5, 80-86 (2007)

10. La Van Thanh, Z.A. Dikaya, The Science and Technical Journal of the Saint Petersburg State Forest Technical University, 6(65), 55-56 (2008)

11. La Van Thanh, Z.A. Dikaya, Modern Aspects of Economics, 10(123), 15-20 (2007)

12. L.P. Mayorova, Rational use of timber as the ecological and chemical basis for the operation of the forest sector (evidence from Khabarovsk Region) (2011)

13. V.I. Patyakin, The Forest Sector of the XXI Century: Materials of the IVth International Forum, 130-132 (2002)

14. I.V. Somina, Social and Humanities Insights, 8, 294301 (2012)

15. V. Somina, Herald of Belgorod Shukhov State Technological University, 4, 142-145 (2013)

16. M.S. Starikova, Herald of Belgorod Shukhov State Technological University, 6, 122 (2014) 
17. A.V. Sukhorukov, News of Saratov University. New Series. Series: Economics. Management. Law, 14, 11-3(52-3), 437-443 (2014)

18. N.A. Tyurin, I.V. Griroryev, O.I. Grigoryeva, Relevant Areas of Scientific Research in XXIst Century: Theory and Pracice, 2, 3(7-3) 2014. DOI: 10.1273/3266.

19. I.I. Shanin, Issues of Innovative Economy, 4(14), 30-39 (2012)

20. E.D. Shchetinina, N.V. Ovcharova, Herald of Belgorod Shukhov State Technological University, 3, 159-163 (2016)

21. V.I. Yagodin, V.A. Sokolova, News of Saint Petersburg State Forest Technical University, 188, 246-252 (2009)

22. Ketels C. Sweden's, Globaliserings forum Rapport, 2 (2012)

23. R. Nelson, National Innovation Systems. A Comparative Analysis (Oxford Univ. Press, Oxford, 1993) 